\title{
Developing a Smart Energy Monitoring Terminal Based on Internet of Things
}

\author{
Shaoru Zhang ${ }^{1}$, Jianjun $\mathrm{Yi}^{2, *}$, Liang $\mathrm{He}^{2,3}$ and Fangwen $\mathrm{Xu}^{1}$ \\ ${ }^{1}$ Department of Mechanical Engineering, East China University of Science and Technology, Shanghai 200237, China; \\ ${ }^{2}$ Shanghai Aerospace Control Technology Institute, Shanghai 201109, P. R. China \\ ${ }^{3}$ Shanghai Key Laboratory of Aerospace Intelligent Control Technology, Shanghai 201109, P. R. China \\ *Corresponding author
}

\begin{abstract}
With the widespread application of power electronics technology, power pollution is becoming more and more serious. Based on the research of existing energy monitoring terminal, an energy monitoring terminal for monitoring and analyzing the power quality based on Internet of Things (IoT) technology is proposed in this paper, the terminal architecture, software flow chart is also provided, and the core circuit is described. Through validation, the terminal, presented in this paper, has some superiority of fully function, simple structure, easy to use and high accuracy, and has a broad market prospect.
\end{abstract}

Keywords—energy monitoring; IoT; data acquisition; wireless communication

\section{INTRODUCTION}

In recent years, with the increasing level of industrial automation in our country, more and more large-scale non-linear loads have been used, seriously affect the power quality of public power grids and the negative influences have also become serious[1]. For example, the extensive use of rectifiers, electric arc furnaces and electric locomotives has brought a series of technical and economic benefits as well as greatly increased the harmonic content of power grids. Harmonic in the power grid will make the transmission and distribution equipment such as rotating electrical machines, transmission lines, transformers and other devices overheat. At present, most domestic power quality monitoring equipment has fewer functions. Foreign companies such as Fluke has a single product category and the product is usually expensive.

IoT is an extension of internet applications, the internet of things and things connected to achieve information management, remote management control and intelligent monitoring[2].The characteristics of information monitoring, automation and interaction of electric energy monitoring determine that the current traditional electric energy monitoring needs to be integrated with IoT technology. As for the electricity monitoring, the energy monitoring device with a single function isn't suitable for power quality monitoring requirement. It is important to develop an energy monitoring terminal with IoT function, which integrates the functions of measurement, communication and analysis to monitor the power quality.

The overall structure of power monitoring terminal is proposed in Section 2. The power data acquisition and process principles, harmonic detection based on Fast Fourier Transform and LoRa wireless communication network are introduced respectively in Section 3. Validation of this terminal is given in Section 4. Summary is drawn in final Section.

\section{DEVELOPMENT OF ENERGY MONITORING TERMINAL}

Aimed at the problems such as high price, fewer interfaces and lacks of flexibility and extensibility of the existing monitoring terminal, the energy monitoring terminal proposed in this paper has the following functions:

(1)Power Quality Monitoring Function: The monitoring terminal measures the basic power indicators and detects voltage deviation, frequency deviation, three-phase unbalance and harmonic content.

(2)Display Function: The monitoring terminal displays the electrical monitoring data and the alarm information on-site.

(3)Communication Function: The power quality monitoring terminal sends the parameters to the remote server through wired or wireless communication.

\section{POWER MONITORING TERMINAL OVERALL STRUCTURE}

Based on the current research on energy monitoring technology, the monitoring terminal utilizes dedicated measurement chip and ARM architecture. Dedicated metering chip is responsible for collecting and processing electrical parameters. The main controller is responsible for reading the data in the dedicated metering chip register. Then the main controller displays and sends the data through the wired or wireless communication. Based on the above design concept, the overall structure of the energy monitoring terminal shown in Figure I.

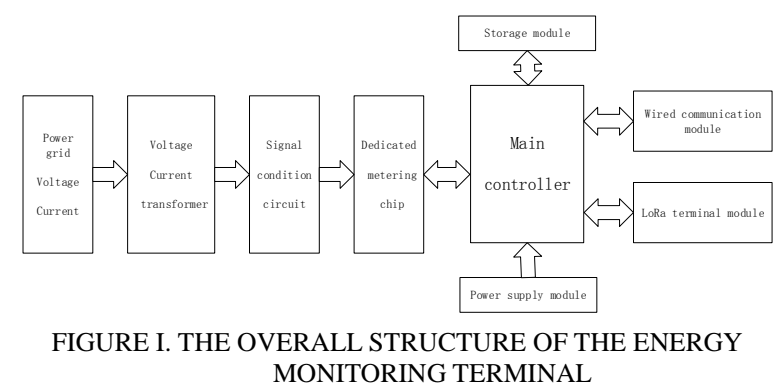

In Figure I, three-phase voltage and current signal of electric equipment input signal conditioning circuit through voltage and current transformers. The signal conditioning circuit is to filter, shape, amplify and impedance matching the signals transmitted 
by transformers, so that the signal range is suitable for dedicated metering chips. The purpose of the dedicated measurement chip is to deal with the signal that output by the signal conditioning circuit. Then the dedicated measurement chip calculates, analyzes the signal, and gets the required energy parameters and indicators. The main controller function is to read the power data in the dedicated metering chip register and it's also responsible for the storage, alarm and communication.

\section{A. Power Data Acquisition and Processing}

The monitoring terminal uses RN7302 as the dedicated measuring chip for data acquisition. The chip is a multi-function and high-precision three-phase energy metering chip, which is suitable for three-phase three-wire and three-phase four-wire applications.

Data acquisition and processing circuit includes voltage signal acquisition, conditioning circuits, current signal acquisition, conditioning circuits, as showed in Figure II, Figure III.

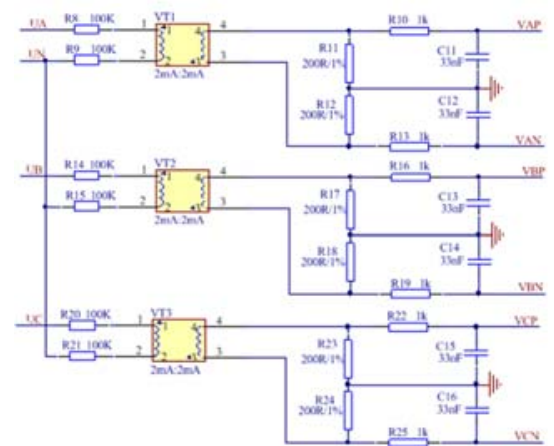

FIGURE II. COLLECTION CIRCUIT OF VOLTAGE SIGNAL

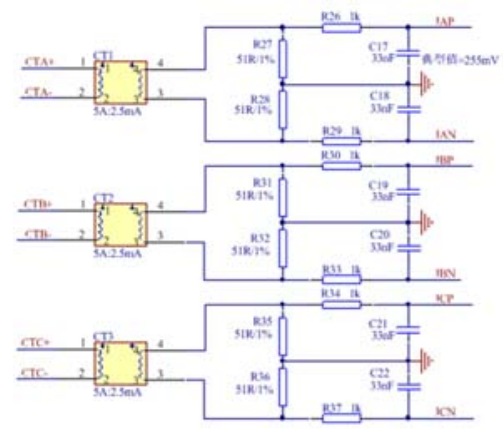

FIGURE III. COLLECTION CIRCUIT OF CURRENT SIGNAL

Figure II is a collection and conditioning circuit of the voltage signal. The DL-PT202H1 voltage transformer is to collect the voltage signal.The transformer is a current type voltage transformer, so add a resistor at its input to convert the measured voltage into current. Through the sampling resistor the current signal will be converted to the voltage signal then the voltage signal inputs the dedicated measuring chip.

The collection and conditioning circuit of the current signal is similar to the circuit of voltage signal. The DL-CT21C2.0 voltage transformer is to collect the current signal. Through sampling resistor, the current signal that output by the transformer will be converted to voltage signal. The voltage signal passes through the filter and inputs the dedicated measuring chip.

The basic parameters of power quality contain RMS voltage, RMS current, active power, reactive power, apparent power and power factor and other parameters, the paper focuses on the description of above parameters. Based on circuit theory, this paper lists the electricity parameter calculation method. The effective values of voltage and current and the formula of active power are shown in equations 1,2,3:

$$
\begin{aligned}
& U_{r m s}=\sqrt{\frac{1}{T} \int_{0}^{T} U^{2}(t) d t} \\
& I_{r m s}=\sqrt{\frac{1}{T} \int_{0}^{T} i^{2}(t) d t} \\
& P=\frac{1}{T} \int_{0}^{T} u(t) i(t) d t
\end{aligned}
$$

$u(t), i(t)$ in the formula represent the analog voltage and current signals. $\mathrm{U}_{\mathrm{rms}}, \mathrm{I}_{\mathrm{rms}}$ respectively represent voltage and current RMS. $\underline{\mathrm{P}}$ represents the active power. This paper discretizes the voltage and current signals, and introduced the voltage and current RMS and active power in discrete domain, respectively, as shown in equations 4,5,6:

$$
\begin{gathered}
U_{r m s}=\sqrt{\frac{1}{N} \sum_{n-1}^{N} u(n)^{2}} \\
I_{r m s}=\sqrt{\frac{1}{N} \sum_{n-1}^{N} i(n)^{2}} \\
P=\frac{1}{N} \sum_{n-1}^{N} u(n) i(n)
\end{gathered}
$$

Energy monitoring terminal applies the dedicated energy metering chip to process the power data, the data acquisition software just reads the data in register. When the monitoring terminal receives the instruction to read the data, it firstly initializes the SPI communication with the metering chip, and then the main controller sends the correspond command to the dedicated measurement chip and waits for the response. The dedicated measurement sends the energy data monitoring data to the main controller.

\section{B. Harmonic Detection Based on Fast Fourier Transform}

Fast Fourier Transform is widely used in the field of signal processing, which samples in one cycle and acquires a series of discrete-time signals. After the analog and digital conversion, these data are sent to the microprocessor for processing [3]. The amplitude and phase of harmonics contained in the voltage and current signal will be calculated by multiplying the conversion factor.

Take a series of discrete time $\left\{f_{\mathrm{k}}\right\}$ assuming that the sequence is evenly distributed on the axis, the corresponding 
time coordinates time coordinates $t=k T / N$, the value of each time point is $f(\mathrm{kT} / \mathrm{N})$.

$$
n w_{1} t=n \frac{2 \pi}{T} \times k \frac{T}{N}=\frac{2 \pi}{N} k n
$$

According to the discrete time series $\left\{f_{\mathrm{k}}\right\}$, the formula for calculating the coefficients $a_{n}$ and $b_{n}$ of the n-th harmonic can be obtained:

$$
\begin{aligned}
& a_{n}=\frac{2}{T} \sum_{k=0}^{N-1} f_{k} \cos \frac{2 \pi}{N} k n \times \frac{T}{N}=\frac{2}{N} \sum_{k=0}^{N-1} f_{k} \cos \frac{2 \pi}{N} k n, n=0,1, \ldots, N-1 \\
& b_{n}=\frac{2}{T} \sum_{k=0}^{N-1} f_{k} \sin \frac{2 \pi}{N} k n \times \frac{T}{N}=\frac{2}{N} \sum_{k=0}^{N-1} f_{k} \sin \frac{2 \pi}{N} k n, n=0,1, \ldots, N-1
\end{aligned}
$$

The main controller adapts128-point Fast Fourier Transform algorithm to extract 0-50 harmonics from the sixchannel synchronous sampling data which are obtained from the dedicated measuring chip voltage and current waveform buffer registers. For example, the main controller sets the dedicated measuring chip to collect the instantaneous value of 128 points in one cycle, the sampling frequency is $6.4 \mathrm{KHz}$. Via low-pass filter dedicated measuring chip suppress highfrequency noise.

\section{LoRa Wireless Communication Network Structure}

The monitoring terminal utilizes the latest IoT wireless communication technology (LoRa) to set up a wireless sensor network for data transmission. LoRa terminal module utilizes microprocessor based on 32-bit Cortex-M3 architecture as the core, equipped with SX1278 based RF module [4]. The module utilizes an efficient cyclic error correction coding algorithm, which has high coding efficiency and strong error correction capability. Under the condition of sudden interference, the module can correct the interfered data packet proactively [5]. The software flow chart is shown in Figure IV.

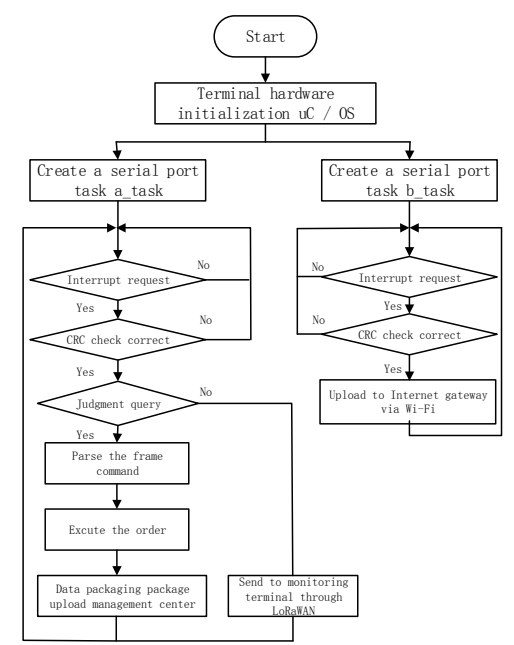

FIGURE IV. LORA TERMINAL MODULE SOFTWARE FLOW CHART

The LoRa wireless network utilizes a star self-organizing network and socket communication based on the TCP / IP protocol to upload the power data to the Internet gateway through the public network, and is also responsible for receiving instructions from the electric energy data center. When the Lora terminal module receives the packet from the energy data center or the packet uploaded from the monitoring terminal, the Lora terminal module performs CRC check on the packet data to ensure that the data is accurate.

\section{VALIDATION OF THE TERMINAL}

\begin{tabular}{|c|c|c|c|c|c|c|c|c|}
\hline $\begin{array}{l}\mathbf{N} \\
\mathbf{O}\end{array}$ & $\begin{array}{c}\text { Fre } \\
\text { que } \\
\text { ncy } \\
\text { (Hz } \\
\text { ) }\end{array}$ & $\begin{array}{c}\text { Vol } \\
\text { tag } \\
\text { e } \\
\text { (V) }\end{array}$ & $\begin{array}{c}\text { Cu } \\
\text { rre } \\
\text { nt } \\
\text { (A) }\end{array}$ & $\begin{array}{l}\text { Three- } \\
\text { phase } \\
\text { unbala } \\
\text { nce } \\
\text { Factor } \\
(\%)\end{array}$ & $\begin{array}{c}\text { Act } \\
\text { ive } \\
\text { po } \\
\text { wer } \\
\text { (W } \\
\text { ) }\end{array}$ & $\begin{array}{l}\text { React } \\
\text { ive } \\
\text { power } \\
\text { (VAr) }\end{array}$ & $\begin{array}{c}\text { Insp } \\
\text { ectin } \\
\text { g } \\
\text { pow } \\
\text { er(V } \\
\text { A) }\end{array}$ & $\begin{array}{c}\text { Po } \\
\text { wer } \\
\text { fact } \\
\text { or }\end{array}$ \\
\hline 1 & $\begin{array}{c}50 . \\
01\end{array}$ & $\begin{array}{c}231 \\
.8\end{array}$ & $\begin{array}{c}1.2 \\
1\end{array}$ & 0.27 & $\begin{array}{c}188 \\
.7\end{array}$ & -16.8 & $\begin{array}{c}282 . \\
8\end{array}$ & $\begin{array}{l}0.6 \\
67\end{array}$ \\
\hline 2 & $\begin{array}{l}49 . \\
98\end{array}$ & $\begin{array}{c}231 \\
.5\end{array}$ & $\begin{array}{c}1.2 \\
2\end{array}$ & 0.20 & $\begin{array}{c}188 \\
.4\end{array}$ & -16.0 & $\begin{array}{c}282 . \\
7\end{array}$ & $\begin{array}{l}0.6 \\
61\end{array}$ \\
\hline 3 & $\begin{array}{l}50 . \\
16\end{array}$ & $\begin{array}{c}231 \\
.7\end{array}$ & $\begin{array}{c}1.2 \\
2\end{array}$ & 0.25 & $\begin{array}{c}188 \\
.2\end{array}$ & -16.5 & $\begin{array}{c}282 . \\
6\end{array}$ & $\begin{array}{l}0.6 \\
65\end{array}$ \\
\hline
\end{tabular}

Table I - Table III is the monitoring power data.

TABLE I. PHASE A MONITORING DATA

\begin{tabular}{|c|c|c|c|c|c|c|c|c|}
\hline $\begin{array}{l}\mathbf{N} \\
\mathbf{O}\end{array}$ & $\begin{array}{l}\text { Fre } \\
\text { que } \\
\text { ncy } \\
\text { (Hz } \\
\text { ) }\end{array}$ & $\begin{array}{l}\text { Volt } \\
\text { age } \\
\text { (V) }\end{array}$ & $\begin{array}{c}\text { Cur } \\
\text { ren } \\
t \\
(\mathrm{~A})\end{array}$ & $\begin{array}{l}\text { Three- } \\
\text { phase } \\
\text { unbala } \\
\text { nce } \\
\text { Factor( } \\
\%)\end{array}$ & $\begin{array}{c}\text { Act } \\
\text { ive } \\
\text { po } \\
\text { wer } \\
\text { (W) }\end{array}$ & $\begin{array}{l}\text { Reacti } \\
\text { ve } \\
\text { power } \\
\text { (VAr) }\end{array}$ & $\begin{array}{c}\text { Insp } \\
\text { ectin } \\
\text { g } \\
\text { powe } \\
\text { r(VA } \\
\text { ) } \\
\end{array}$ & $\begin{array}{c}\text { Po } \\
\text { wer } \\
\text { fact } \\
\text { or }\end{array}$ \\
\hline 1 & $\begin{array}{c}49.9 \\
9\end{array}$ & $\begin{array}{c}231 . \\
4\end{array}$ & 1.21 & 0.24 & $\begin{array}{c}188 . \\
5\end{array}$ & -16.7 & 282.7 & $\begin{array}{c}0.66 \\
7\end{array}$ \\
\hline 2 & $\begin{array}{c}49.9 \\
8\end{array}$ & $\begin{array}{c}231 . \\
7\end{array}$ & 1.22 & 0.25 & $\begin{array}{c}188 . \\
7\end{array}$ & -16.1 & 282.6 & $\begin{array}{c}0.66 \\
1\end{array}$ \\
\hline 3 & $\begin{array}{c}50.0 \\
1\end{array}$ & $\begin{array}{c}231 . \\
7\end{array}$ & 1.22 & 0.27 & $\begin{array}{c}188 . \\
3\end{array}$ & -16.6 & 282.7 & $\begin{array}{c}0.66 \\
6\end{array}$ \\
\hline
\end{tabular}

TABLE II. PHASE B MONITORING DATA

\begin{tabular}{|c|c|c|c|c|c|c|c|c|}
\hline $\begin{array}{l}\mathbf{N} \\
\mathbf{O}\end{array}$ & $\begin{array}{c}\text { Fre } \\
\text { que } \\
\text { ncy } \\
\text { (Hz } \\
\text { ) }\end{array}$ & $\begin{array}{l}\text { Volt } \\
\text { age } \\
\text { (V) }\end{array}$ & $\begin{array}{l}\text { Cur } \\
\text { rent } \\
\text { (A) }\end{array}$ & $\begin{array}{c}\text { Three- } \\
\text { phase } \\
\text { unbala } \\
\text { nce } \\
\text { Factor( } \\
\%)\end{array}$ & $\begin{array}{c}\text { Acti } \\
\text { ve } \\
\text { pow } \\
\text { er } \\
\text { (W) }\end{array}$ & $\begin{array}{l}\text { Reacti } \\
\text { ve } \\
\text { power } \\
\text { (VAr) }\end{array}$ & $\begin{array}{c}\text { Insp } \\
\text { ectin } \\
\text { g } \\
\text { powe } \\
\text { r(VA } \\
\text { ) }\end{array}$ & $\begin{array}{c}\text { Po } \\
\text { wer } \\
\text { fact } \\
\text { or }\end{array}$ \\
\hline 1 & $\begin{array}{c}50.0 \\
1\end{array}$ & $\begin{array}{c}231 . \\
7\end{array}$ & 1.21 & 0.22 & $\begin{array}{c}188 . \\
3\end{array}$ & -16.7 & 282.8 & $\begin{array}{c}0.66 \\
5\end{array}$ \\
\hline 2 & $\begin{array}{c}49.9 \\
7 \\
\end{array}$ & $\begin{array}{c}231 . \\
5\end{array}$ & 1.22 & 0.25 & $\begin{array}{c}188 . \\
7 \\
\end{array}$ & -16.4 & 282.6 & $\begin{array}{c}0.66 \\
6 \\
\end{array}$ \\
\hline 3 & $\begin{array}{c}50.0 \\
2\end{array}$ & $\begin{array}{c}231 . \\
6\end{array}$ & 1.22 & 0.25 & $\begin{array}{c}188 . \\
4\end{array}$ & -16.6 & 282.7 & $\begin{array}{c}0.66 \\
5\end{array}$ \\
\hline
\end{tabular}

TABLE III. PHASE C MONITORING DATA

The left picture in Figure $\mathrm{V}$ shows the real-time waveform of the A-phase voltage of the measurement chip. The right picture shows the 1-10th harmonic values after the Fast Fourier Transform.

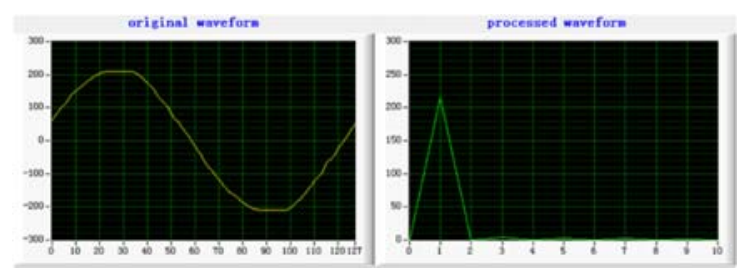

FIGURE V. MEASUREMENT CHIP REAL-TIME WAVEFORM AND HARMONIC VALUES 
The test results show that the power monitoring terminal meets the design requirements. In the dynamic range of 5000:1, the nonlinear error of measuring chip is less than $0.1 \%$ and the accuracy of monitoring terminal reaches $0.2 \mathrm{~S}$ level.

\section{SUMMARY}

The power quality monitoring terminal based on embedded and Internet of Things (LoRa) technology is discussed in this paper. Energy monitoring terminal is not only conducive to the energy sector to strengthen the regulation of energy system and improve regulation of energy grid but also provide decisionmaking basis for the management of power quality.

\section{ACKNOWLEDGMENTS}

This paper was supported by the Military and civilian integration project(Shanghai economic and information commission) under Grant No.201720, the Natural Science Fund of China (NSFC) under Grant Nos. 51575186, 51275173, and 50975088, the Fundamental Research Funds for the Central Universities under Grant No. WH0913009, Shanghai Pujiang Program under Grant No. PJ201000353, and Shanghai Software and IC industry Development Special Fund under Grant No. 120493.

\section{REFERENCES}

[1] Bollen M H J. Understanding Power Quality Problems - Voltage Sags and Interruptions J.IEEE Press Series on Power Engineering,2000,15(9):112-117

[2] Rafiei, M. Elmi, S \& Zare, A. (2012). Wireless communication protocols foe smart metering applications in power distribution networks. In: Electrical Power Distribution Networks (EPDC), 2012 Proceedings of 17th Conference on.

[3] Andria G, Savin M, Trotta A. Windows and interpolation algorithms to improve electrical measurement accuracy J. IEEE Trans on Instrumentation and Measurement.38(4): 856-863.

[4] Malasani R. Long-distance wireless-LAN directional antenna alignment: US, US8462066 P.2013.

[5] Mohamed Aref, Axel Sikora, Free Space Range Measurements with Semtech LoRaTM Technology A.2014 2nd International Sympo-sium on Technology and Applications(IDAACS-SWS).Of-fenburg,2014,19-23. 